\title{
OPERADORES DE PREFERENCIA
}

\author{
Catalina Fuentes Rodriguez \\ Universidad de Sevilla \\ Grupo de investigación "Argumentación y persuasión en Lingüística" \\ cfuentes@us.es
}

\section{Resumen}

Este artículo estudia los adverbios que marcan preferencia. Estos seleccionan un elemento que el hablante elige de un paradigma. Se describe su comportamiento en los niveles informativo, argumentativo y enunciativo.

PALABRAS CLAVE: pragmática, adverbio, preferencia, operador, sintaxis.

\begin{abstract}
This article study the adverb which mark preference. They select an element that the speaker choose into a paradigm. The author describes their behaviour in the level of the information, argumentation and enunciation.

KEY WORDS: pragmatics, adverb, preference, operator, syntax.
\end{abstract}

\section{Introducción}

Existe un grupo de adverbios en español que funcionan como operadores informativoargumentativos y comparten una zona significativa y unas características sintácticas. Nos referimos a sobre todo, más que nada, antes que nada, ante todo, particularmente, especialmente, principalmente, fundamentalmente, básicamente, predominantemente, primordialmente, preponderantemente, preferiblemente, preferentemente'. Formalmente parecen constituir dos grupos diferentes. Pero su funcionamiento es idéntico, en un contexto bien definido.

Es frecuente verlos en la bibliografía relacionados entre sí. Así, L. Santos Río en Apuntes paralexicográficos ${ }^{2}$ define principalmente como equivalente a fundamentalmente, antes que nada, sobre todo, primordialmente. Y nos dice que suele imponer carácter focal en el sintagma que le sirve de alcance, el cual puede a veces no precederlo o precederlo de forma no inmediata.

Han sido estudiados también en francés los equivalentes a sobre todo y particularmente (J. C. Anscombre: 2001 o H. Nolke: 2001). Estas unidades comparten función y características formales. Han sido llamadas por H. Nolke (1983 y 1988) "paradigmatizantes", junto a otros adverbios del tipo de solamente, que no estudiamos aquí. Estos adverbios:

1 Este estudio se realiza dentro del Proyecto "Diccionario de Conectores y operadores del español", que goza de una ayuda del Ministerio de Ciencia y Tecnología: BFF 2002-1628, y está cofinanciado con fondos FEDER.

2 Este estudio sobre los adverbios en -mente está retomado en su obra de 2003. 
- presuponen otros elementos que formarían parte de un paradigma, del que se destaca un elemento: el foco. Su enunciación implica que también otros elementos cumplen la predicación.

- Afectan a una función sintáctica, a un participante en el enunciado. Este es el ámbito sintáctico sobre el que operan, "le noyau" según H. Nolke.

- Algunos autores hablan de una gradación entre los miembros del paradigma ( $\mathrm{H}$. Nolke), y un valor argumentativo añadido, como efecto. Otros lo consideran procedimientos de enfatización, de relieve informativo (así L. Santos Río).

Por nuestra parte, hemos llamado a estas unidades operadores de preferencia ${ }^{3}$. Veamos por qué:

- Pueden aparecer antepuestos o pospuestos al adjetivo, integrados entonativamente o entre pausas.

"Está borracho, más que nada" (ante todo, sobre todo, ¿antes que nada?)

- Su acción se restringe al enunciado al que afecta, y se focaliza sobre un segmento de la predicación. No conectan, no exigen un enunciado anterior, aunque por su significado presupongan una serie.

- No tienen función sintáctica con respecto al verbo de la oración.

- Indican preferencia enunciativa del término que modifican frente a otros (serie implícita o explícita) situados en una escala argumentativa. Lo presentan como el término más adecuado a la intención comunicativa del hablante, el que define mejor a esa realidad.

Sus contextos de aparición son:

1) Puede aparecer el adverbio solo: en estos casos se encuentra implícita la serie o paradigma. El operador marca la enfatización del segmento afectado por encima del grupo al que pertenece.

2) Puede explicitarse la serie bien a través de una enumeración coordinativa, o de una estructura restrictiva:

a) A, B, y (operador) C: A, B y C son de la misma serie o paradigma.

b) A, (operador) a1: A: elemento general hiperónimo; a1: un elemento concreto hipónimo. Esta estructura restrictiva, al aparecer entre pausas, supone una reinterpretación ${ }^{4}$ del hablante, que matiza lo dicho tras su primer intento comunicativo y reduce su extensión.

La preferencia puede expresarse de diversos modos, bien basándose en una especialización de una característica semántica denotativa, evaluativa (especialmente, preferentemente, 
preferiblemente, particularmente, primordialmente, preponderantemente, principalmente, básicamente) o bien tras un proceso de lexicalización y gramaticalización de expresiones circunstanciales que utilizan preposiciones o adverbios + cuantificadores genéricos: todo o nada. Notemos que tanto las preposiciones (sobre, ante) o los adverbios (antes, más) y los pronombres cuantificadores (nada, todo) suponen una posición elevada en una escala (en dirección ascendente o descendente).

Constituyen, pues, un paradigma claramente delimitado, que, como vemos, presenta unos empleos comunes, aparte de los usos específicos que podemos encontrar en cada uno de ellos.

\section{Los operadores sobre todo, máxime, ante todo, antes que nada, más que nada}

\subsection{Sobre todo}

Es el operador de preferencia prototípico. Está constituido por un sintagma nominal en su origen (preposición + pronombre), gramaticalizado, que funciona como operador informativo y argumentativo. Actúa sobre un sintagma, en cualquier función sintáctica. Lo pone de relieve por encima de otros que podrían aparecer en ese lugar. Pertenece, pues, a los que H. Nolke (1983) llamó "paradigmatisants". Es decir, presupone otros elementos de la misma serie, del mismo paradigma, pero presenta la preferencia del hablante por el elegido en el enunciado.

Aparece generalmente antepuesto al elemento al que afecta (verbos, participios, adjetivos, adverbios y sintagmas nominales circunstanciales) e integrado en su grupo fónico. En ocasiones lo encontramos entre pausas y como comentario pospuesto alguna vez. Parece resaltar la función, la participación del sintagma $\mathrm{X}$ como argumento o participante del verbo.

J. C. Anscombre (2001) ha analizado su homónimo en francés (surtout) y ha encontrado los siguientes valores:

1) adverbio de frase (equivalente a "en plus")

2) combinado con que, es un adverbio de enunciación (aparece en recomendaciones). Está próximo al uso interjectivo (en respuesta). Considera que afecta a parte o a todo un sintagma. Se combina con sintagmas nominales con o sin preposición, antepuesto o pospuesto. No se focaliza. No aparece al inicio de la frase si no es toda ella el foco. Acepta la posición en inciso.

Anscombre descubre un valor discursivo devaluador ${ }^{5}$ en el contexto: "Q: P1, sobre todo P2". En él Q es una conclusión que surge de P2 o de la negación de P1.

Asimismo, reconoce en esta unidad un valor argumentativo: surtout exige la coorientación de los argumentos. Podría objetarse que entonces no sería posible "mais surtout". Según él sí, porque operan en dos niveles distintos. En realidad se debe a que mais no antiorienta necesariamente, sino que manifiesta diferencia de fuerza argumentativa. 
En español lo encontramos precediendo a un segmento, entre pausas, concentrando el interés informativo sobre él:

Como los demás. Cada cuatro años. Sale de una comisión, ¿en qué estaban ahora? Pues ahora estamos en la comisión que está dándole el último vistazo a la ortografía que va a publicar la Academia, teniendo en cuenta, sobre todo, las últimas observaciones que nos han llegado de algunas Academias Americanas (Hoy por hoy, 24/04/99, Cadena SER).

\section{O en posición posterior:}

(...) y entonces se complementan un montón, y bueno, y eso, y todo lo que tiene de ordenada Diana, porque Diana es superordenada, superresponsable, pues Alba no lo tiene, y entonces pues la otra le dice: Alba, no sé qué, ordena tus cosas, tal y por esa razón están todo el día discutiendo, pero, bueno, se quieren un montón. Y Alba sobre todo, pues la apoya muchísimo y es que es supercariñosa (Entrevista CSC008, mujer, 20 años, 1998).

Aparte de este empleo de focalización de un sintagma, precedente o siguiente, sobre todo tiene un contexto específico de uso: un enunciado general + un sintagma con sobre todo, que reduce la aplicación de lo dicho en el primero a un segmento, a una parcela. Es una estructura restrictiva, más frecuente con circunstancias. $Y$ así encontramos modales, condicionales, temporales, etc.

Esta construcción es muy frecuente: Sobre todo introduce un aspecto en el que la validez de lo dicho aparece sobrepotenciada. Es decir, actúa como un sobrerrealizante ${ }^{6}$. Reduce la referencia pero aumenta la fuerza argumentativa. Lo dicho en el enunciado general se afirma para todas las situaciones. A continuación, la restricción introducida por sobre todo lo limita a un aspecto, elegido sin anular los demás. En esto consiste la reinterpretación.

Lo que pasa que en Santiago hay muy pocas que den asignaturas de filologia. sobre todo de inglesa. Pero están muy bien pagadas (Entrevista CSC003, hombre, 22 años, 1998).

El hablante afirma primero que existen pocas academias con clases de filología, y luego lo restringe a las de inglesa, que de este modo se potencian. Igual en los casos siguientes:

No, hablas fuera igual, te entienden lo mismo, sobre todo si quieren cobrar (CSC001, hombre 23 años, 1998)

Cuando quieren cobrar es cuando mejor entienden.

Obviamente tiene como misión principal defender los derechos de los mismos, sobre todo cuando son objeto de algún tipo de discriminación (Sexta Edición, 10-12-98, Radio Rivadavia).

En Galicia, el Cantábrico y la meseta, también la mitad occidental de Andalucía, el tiempo será como el de ayer, nubosidad abundante, chubascos intermitentes y alguna tormenta moderada, sobre todo por la tarde (Hoy por hoy, 24-4-1999, Cadena Ser). 
En aclaraciones:

Entonces la mayor parte de mis compañeros, sobre todo compañeras, que lo hacían más las mujeres, tienen la especialidad de Historia, tienen la especialidad de Geografia hecha y tienen incluso la especialidad de Arte (Entrevista CSC011, hombre, 47 años, 1998).

En algún caso introduce dos elementos y vuelve sobre el segundo para manifestar su elección de forma clara: A y B, sobre todo B:

Pero en Navidad y verano si, sobre todo en verano, como eran largas las vacaciones aquí en Santiago, meses de julio y agosto, pues venía a ser como un desierto (Entrevista CSC011, hombre, 47 años, 1998).

También lo podemos encontrar en enumeración: aparece tras $y, \mathrm{y}$ une elementos cohipónimos, concretos todos:

En los países más pobres también, claro, porque eso pues tiene a las gentes aisladas en su propia lengua. Bueno, pues las lenguas de con peso, las lenguas no analfabetas, las lenguas escritas y sobre todo una lengua como la nuestra, que es la segunda del mundo de hecho en dimensión y en en uso internacional que se extiende por un ámbito enorme que no es seña de identidad de nadie, no porque para somos demasiados, es una lengua plurinacional y multiétnica, y eso es lo que debe llenarnos, por lo menos, de satisfacción porque ...(Hoy por hoy, 24/04/99, Cadena SER).

Como podemos comprobar por los ejemplos citados, sobre todo es un operador complejo. Tiene un contenido presuposicional. Presupone un paradigma de elementos en el que establece una reducción de la referencia a uno concreto, el elegido o preferido. Esta, la preferencia, es una actividad enunciativa. Pero, además, esa elección del hablante provoca una enfatización o relevancia informativa y argumentativa del elemento que destaca.

Para H. Nolke, sobre todo añade una información de gradación. Y esta aparece como una información nueva. Así, el ejemplo que añaliza H. Nolke (1983):

"Pierre mange surtout des gâteaux", significa lo siguiente, según él:

«a.Pierre mange des gâteaux

b. Pierre mange autre chose que des gâteaux

c. Pierre mange des gâteaux d'un degré supérieur au degré auquel il mange autre chose » (109)

$\mathrm{Y}$ añade las siguientes caracteristicas:

- Si el "noyau" es un adverbial de causa o fin, la gradación opera sobre la importancia de las causas (o de las finalidades)

- Si el verbo está marcado por una gradación, la gradación se establece a partir de él

- La gradación opera sobre cantidades mensurables

- La gradación trabaja sobre la frecuencia del proceso o del acto denotado en la frase. 
Considera que tiene un valor argumentativo, pero la gradación no se identifica con él.

En nuestra opinión, más que gradación habría que hablar de escala argumentativa. Los elementos que presupone como constituyentes del paradigma están organizados en una escala de importancia o relevancia argumentativa. Potencia la fuerza argumentativa del elemento. En el ejemplo anterior de "gateaux" sería un sobrerrealizante, sobre todo en los casos de reinterpretación.

Según nuestro análisis, las características de sobre todo y, por extensión, de un operador de preferencia son:

- presupone otros elementos además del introducido, un paradigma que cumpliría la predicación. El paradigma se sitúa en el plano de la presuposición. Es un adverbio de tipo presuposicional, en cuanto a su contenido.

- En el paradigma establece una escala argumentativa, una escala de fuerza: sobre todo marca la preferencia o el grado más elevado de aparición. Esto se halla en la afirmación. Informa que se da en ese elemento, y que este es el que el hablante privilegia, el que prefiere frente a otros, porque es el que cumple los requisitos más que los otros.

- Es de naturaleza escalar

- Focaliza el sintagma sobre el que recae

- Es un operador informativo-argumentativo. Actúa dentro del enunciado, afectando a un núcleo sintáctico, a una función y establece la preferencia o relevancia de la misma.

- Puede preceder o seguir al segmento, y aparece en ciertos contextos:

a) solo en un enunciado dota de relieve a una función. Presupone el paradigma

b) en enumeración, $+y$ : el paradigma o la escala está explícita

c) + pero: marca la preferencia informativa o argumentativa explícita por el segundo segmento

d) en estructura restrictiva de reinterpretación (Enunciado completo general, seguido de una circunstancia o una concreción, hiperónimo-hipónimo) introduce un sobrerrealizante.

Esta función que cumple sobre todo en cualquier tipo de texto, oral o escrito, coloquial o formal, se extiende a otras unidades. Estas añaden, además, algunas características específicas a la función de preferencia.

\subsection{Máxime}

Este operador tiene un contexto más restringido que sobre todo. Podríamos describirlo del siguiente modo:

- es un operador culto

- aparece sólo en estructuras de reinterpretación, de restricción: Enunciado general, máxime + circunstancias

- No aparece entre pausas, no forma grupo entonativo. Se integra en el del segmento que introduce. 
- Actúa como introductor de un sobrerrealizante, un argumento de mayor fuerza argumentativa.

Podemos verlo en los siguientes ejemplos:

Las entidades han destacado que el negocio típico bancario en España ha tenido una evolución muy humana, máxime teniendo en cuenta que la economía mundial ha atravesado en estos meses una mala situación (El País, 30-10-2002).

El vicepresidente segundo de la Cámara, Carmelo Barrio (PP), consideró una 'barbaridad' la decisión de Atutxa, máxime con tantas iniciativas pendientes" (El Diario Vasco, 31-12001).

Durante el reinado de Enrique IV de Castilla, el medio hermano de Isabel la Católica, es explicable que hubiese una relativa permisividad, máxime cuando su conducta sexual se encontraba bajo sospecha (J. Miralles: Hernán Cortés. Inventor de México. México, 2001, 376).

En todos estos casos introduce una circunstancia, un argumento que potencia la fuerza argumentativa de lo anterior. Es el ámbito en el que lo dicho en la oración principal se cumple de forma más clara o más intensa. El marco argumentativo ${ }^{7}$, en suma.

Supone, pues, dos movimientos enunciativos: una aserción y una vuelta sobre ella reduciéndola en sus límites a un marco concreto.

\subsection{Ante todo}

En este caso el operador utiliza otra combinación originariamente de lugar o tiempo: la preposición ante + el cuantificador todo. Lo podemos encontrar focalizado sobre el complemento directo:

Saber que cuando hablamos de reconciliación, tenemos ante todo en mente a la parte del sector popular que te ha estado siguiendo, a quienes conforman el grueso de corriente política que por estos tiempos ha llevado tu nombre, cuyos derechos a la actividad política $\mathrm{y}$ al desarrollo de su partido tienen en todo caso que quedar firmemente garantizados ( $\mathrm{El}$ Universal, 09/10/2003).

Sobre el término del participio referida:

En una conversación mínima, referida ante todo a próximos encuentros, esta simpática mujer, conocida por su espléndida voz, animadora de programas de televisión, madre amantísima (Trabajadores. Órgano de la Central de Trabajadores de Cuba, 19/12/2003).

Aparece entre pausas, como inciso, destacado, referido a todo el sintagma verbal:

Lo que quiero decir es que hay enunciados cuyo sentido principal es ofrecer información, o sea, representar los acontecimientos comunes y externos a los interlocutores de la comunicación, y preguntas que son respuestas a quien, ante todo, solicita que se le informe y no que se opine (Revista Telos, 01-03/2004, nº 58, Segunda Época).

7 Cfr. C. Fuentes-E. Alcaide (2002: 39-40). 
En todos los casos anteriores y los que vamos a ver a continuación está antepuesto, aunque tiene movilidad y podría seguir al elemento al que focaliza. Puede ir aislado o integrado en el mismo grupo fónico. La diferencia es de énfasis.

Los socialistas queremos un Estado que se inspire, ante todo, en el principio de solidaridad con los ciudadanos menos favorecidos (El Socialista, $n^{\circ} 651,04 / 2003$ ).

Su obra representa ante todo las angustias frente a la dictadura de Duvalier (Revista Artes en Santo Domingo, Año 2, no 7, 04-07/2003).

La marca tiene la imagen de un producto ante todo barato en su adquisición, aunque sus usuarios, según señalan las encuestas, se muestran satisfechos con sus prestaciones y fiabilidad (El Mundo - Motor (Suplemento), 03/01/2003).

El elemento presentado es el elegido por el hablante para cumplir la predicación.

\subsection{Antes que nada}

Este operador está muy relacionado en su constitución léxica con el anterior, pero presenta un menor grado de gramaticalización. Presenta una visión lineal. Indica anterioridad. Primer puesto de una sucesión (difícil referirlo a elementos de persona) frente a sobre todo, que se centra en la importancia, la posición por encima, en visión vertical, no horizontal.

Suele aparecer antepuesto con o sin pausa marcada, y afectando a diversas funciones sintácticas:

La preferencia por CA no está mantenida por ningún juicio de valor sino, sencillamente, porque "Cántico" se escribió así en su origen, aunque también debo decir que no fueron razones poéticas precisamente las que motivaron a San Juan a buscar nuevas ordenaciones. Nos enfrentamos, antes que nada a un extraordinario "hecho de lenguaje", anterior incluso a los contenidos semánticos que la razón después le dará (San Juan de la Cruz, n ${ }^{\circ}$ 31-32, 01-02/2003).

Jerónimo López Mozo es antes que nada un hombre de teatro inasequible al desaliento, un autor que ha escrito mucho pero publicado en formato de libro en mucha menor cantidad y estrenado a nivel comercial infinitamente menos, ya que durante el franquismo la censura no le dio de paso en torno al $75 \%$ de las piezas que presentó para su dictamen, generalmente por motivaciones ideológicas, dado su contenido crítico, aunque simbólico, con el régimen dictatorial imperante (La Ratonera. Revista asturiana de Teatro, 01/2002).

En el caso siguiente recae sobre toda una enunciación, modalmente marcada:

Sócrates: ¿Y qué me dices de esto otro? ¿No te parece que cada cosa tiene una esencia lo mismo que un color y cuantas propiedades citábamos hace un instante? $Y$ antes que nada, ¿el color mismo y la voz no tiene cada uno su esencia, lo mismo que todo cuanto merece la predicación de ser? Hermógenes: Pienso que sí (Espéculo. Revista de estudios literarios, 06/2003).

Su escaso grado de gramaticalización hace que esté todavía muy cercano de su valor léxico. Nada es un elemento con referencia no personal, lo que hace que en casos en que afecta a sintagmas con sustantivos de referencia humana, la acción de antes que nada se desplace al verbo, a la acción en sí, más que al objeto. Veámoslo en el ejemplo siguiente: 
La declaración repetida de que fue Valera el autor principal de la NC, tanto en la HR como en el EI, es importante, no sólo para determinar la paternidad de esta obra, sino también porque la $\mathrm{NC}$ era el instrumento con el cual Valera pensaba llegar, antes que nada, al Rey y comunicarle su utopía, para así obtener el reconocimiento cultural y político de su gente, los indios; en una segunda etapa quería llegar a todos los peruanos para que conocieran sus propuestas referentes a la solución de la babélica situación en la cual vivía el Perú tras la conquista (Espéculo. Revista de estudios literarios, 06/2003).

Antes que nada privilegia la acción de "llegar al rey" frente a otras acciones. No "al rey" frente a otros objetos. En ese caso deberíamos decir "antes que a nadie". Los sustantivos, pues, suelen ser inanimados.

Desde el marxismo, Adolfo Sánchez Vásquez realiza una exploración de las postulaciones posmodernas y señala que antes que nada es una perspectiva que niega la médula de la modernidad, es decir sus proyectos de emancipación (Revista Comunicación, v. $12, \mathrm{n}^{\circ} 1$, 03/01/2002).

Su desgracia es así minimizada y las pobres que padecen tales defectos se ven una vez más culpadas por ello. Las contrahechas o jorobadas son feas antes que nada. Cualquier defecto corporal es considerado como una falta de belleza (Giménez Bartlett, A.: La deuda de Eva).

A veces aparece unido a sobre todo para enfatizar el contenido de preferencia:

Es importantísimo tener en cuenta que para el pensamiento del medievo la exégesis bíblica interpreta antes que nada y sobre todo hechos y no palabras (Revista Femenina. Suplemento de El Diario, 15/04/2004).

\subsection{Más que nada}

Lo mismo sucede con más que nada, semejante también en su composición. Su valor es cercano al de sobre todo, aunque menos frecuente que él. Puede anteponerse o posponerse al elemento al que afecta. Es un elemento escalar, ponderativo.

A los otros ya no les preguntamos, por vergüenza más que nada (El Mundo - Vino (Suplemento), 03/01/2003).

"Cuando deambulo por la noche - dice el padre Arnould-- no llevo ningún signo distintivo. No porque sienta vergüenza de mi sacerdocio, sino más que nada por discreción (La Razón, 09/04/2003).

Más que nada parece más popular o coloquial que sobre todo.

\section{Adverbios en -mente}

Esta operación significativa tiene su medio más explicito en los adverbios preferentemente, preferiblemente. El DRAE los considera equivalentes a "con preferencia". Pero s.v. preferir, apunta a otros elementos: antes, más bien, que no comparten los mismos contextos ni el mismo valor que los que estamos viendo aquí. Nosotros hablamos de adecuación informativa y preferencia enunciativa. $Y$ aquellas unidades parecen entender preferencia en 
el sentido de elegir una opción y anular otras. Más bien indica un acercamiento a lo dicho. Sobre todo, especialmente, fundamentalmente realizan una afirmación rotunda de esa característica como la mejor o más adecuada, presuponiendo también la serie a la que pertenece. Véase la diferencia entre:

Es más bien caro / Es sobre todo caro

El efecto argumentativo es completamente distinto. El primero es un mecanismo de atenuación, el segundo de enfatización.

\subsection{Preferentemente- preferiblemente}

Quizás preferentemente y preferiblemente no estén gramaticalizados en esta función, sino que mantienen su contenido semántico originario. En estos dos podemos ver claramente el origen de esta clase de operadores. Es decir, nos permitirá acercarnos al concepto de preferencia. L.Santos Río $(1994,217)$ nos dice, con respecto a preferentemente, lo siguiente:

1. "Con preferencia, sobre todo. Estas dos partículas se emplean preferentemente en contextos de réplica.

2. Con especial aceptación, con preferencia sobre los demás. Se tomarán en consideración las solicitudes formuladas por titulados superiores de ramas técnicas, preferentemente ingenieros y arquitectos".

La diferencia entre estas dos acepciones parece estar en que los elementos del paradigma en 2 están expresos y en 1 no.

Preferiblemente se considera un adverbio oracional, frente al anterior. En preferiblemente nos dice:

"Es preferible (que), con preferibilidad. Aunque puede usarse propiamente como adverbio oracional de modalidad, normalmente en contextos volitivos (Preferiblemente, vas (IND.) tí ('es preferible que vayas (SUBJ.) tú')), su empleo más típico tiene lugar como elemento modificador de sintagmas inferiores. $Y$ así, se antepone a adjetivos de varios tipos, a participios de verbos transitivos e inacusativos y a todo tipo de complementos. Consigueme una parcela, preferiblemente amplia, con riego y en lugar alto" (L. Santos: 1994, 217).

Aquí se ve que la preferencia puede expresarse de modo absoluto o relativo, como una elección, con la serie expresa o implícita.

En el CREA hemos encontrado los siguientes ejemplos:

La lista combina la presencia de políticos y gestores, jóvenes y seniors, afiliados e independientes, y parece haberse buscado preferentemente personas con experiencia de gobierno en las autonomías o con un perfil de eficacia profesional (El País, 01/04/2004).

Si lo interpretamos como un modificador del verbo ("buscar de forma preferente"), no expresamos la focalización sobre personas. Es, pues, un operador. Modifica a la relación buscar- personas. 
Se deberán utilizar preferentemente alimentos ricos en hidratos de carbono complejos (cereales, patatas, verduras, leguminosas, etc.), importante fuente de fibra y nutrientes y conseguir dietas con alta densidad de los mismos (A tu salud. Suplemento Salud de La Razón digital, 15-21/04/2004).

La sustitución por sobre todo es perfectamente posible en estos contextos. No en el siguiente, que aparece entre el auxiliar y el participio.

Una vez colocado el mulch en terreno, deberá comenzar el proceso de plantación. Estas plantas deberá ser preferentemente certificadas libres de nematodo dorado por el SAG. y con coronas no inferior a 5 milímetros de diámetro (Campo Sureño. Suplemento de El Diario Austral, 09/02/2004).

En el siguiente modifica a un adjetivo, contexto poco frecuente para sobre todo, aunque sí para otros adverbios, como especialmente, particularmente, que tienen un contenido semántico evaluativo.

Las placas de Manuel Gómez Miralles captarán durante su extensa labor, desde la alta sociedad costarricense hasta las vendedoras ambulantes o los obreros de las minas de Abangares. Con su visión preferentemente horizontal, prefirió la foto exterior, la toma de calle, que la de estudio (Art Studio Magazine, $\mathrm{n}^{0}$ 6, 02-03/2004).

Igual nos ocurre con preferiblemente:

Debe ser completa y aportarte más energía para seguir adelante el resto de la tarde. Te conviene consumir alimentos preferiblemente preparados al vapor, al horno, a la plancha o en la olla express y variados (Vida y Salud. Suplemento de El Diario, 31/03/2004).

Cuando se combina con adjetivos, pues, no son sustituibles por sobre todo. Este, en todo caso, podría posponerse a él: "alimentos preparados sobre todo al vapor". Sin embargo, el valor es distinto. Preferentemente y preferiblemente en estos contextos parecen guardar el valor evaluativo de su base léxica. No actuarían, por tanto, de forma tan clara como operador de preferencia.

Estos adverbios han aparecido en nuestra búsqueda en posición antepuesta. Esto no quiere decir que no puedan posponerse a su ámbito, aunque en este caso necesitan una pausa. Esta doble posición es más frecuente en el resto de los operadores de preferencia.

\subsection{Predominantemente}

Según L. Santos Río $(1994,217)$, es un adverbio modal y de cantidad:

"Con predominio, en situación de predominio, sobre todo. Se usa especialmente ante adjetivos relacionales clasificativos, sean o no aspectivos, o locuciones equivalentes. Una zona predominantemente industrial. Sus habitantes son predominantemente de raza negra"

Pero este elemento no está gramaticalizado. No es un operador, sino un adverbio modal y cuantificador. Indica predominio de un rasgo en su exensión. Suele combinarse con adjetivos relacionales y circunstancias. 
(...)aspira a sembrar raíz en el arsenal memórico de sus iluminaciones interiores, porque sin duda alguna sentía desde aquellos decenios, la afectación propia de un intelectual y pensador cultural que veía y sentía que su propio pais, predominantemente mulato y negro, sufría y aún sufre de una terrible "afectación bovarista", fenómeno maldito, que atacaba y todavía ataca a un significativo segmento de la cultura y la sociedad dominicana (Revista Artes en Santo Domingo, Año 2, $n^{\circ} 7,04-07 / 2003$ ).

En este caso el hablante nos dice que el país en su mayoría está formado por mulatos, no que sea mulato sobre otras calificaciones, contenido que mostraría un operador de preferencia.

\subsection{Preponderantemente}

Parece todavía cercano a su valor léxico, pero se combina con adjetivos con valor de preferencia también:

Su finalidad no es preponderantemente económica ni tiene propósitos de lucro y es ajeno a intereses políticos, religiosos y raciales (Proceso, 25-8-1996).

Aquí sí se afirma lo económico como característica privilegiada frente a otras. En posición pospuesta debe ir precedido de pausa:

Los fenómenos reactivos son automáticos, preponderantemente, generados por modificaciones funcionales del tejido neural de carácter bioquímico y biofísico como la excitabilidad, conductividad y la transmisibilidad (Revista de Psicología, XI, I, 2002).

Es un adverbio de grado para L. Santos Río (1994 y 2003).

\subsection{Primordialmente}

Supone un paso más en el acercamiento al operador de preferencia. Indica posición privilegiada del elemento elegido en la escala. Parece estar cercano a no aceptar la posibilidad de otros. Quizás también sea más culto. Aparece modificando a un sintagma y es raro en estructuras de reinterpretación. Supone preferencia, sin más.

Esta nueva tendencia se basa en la convicción de que las acciones desarrolladas para mejorar la calidad de los servicios médicos deben dirigirse primordialmente a la disminución del sufrimiento y el incremento del bienestar general de los pacientes, sin descuidar el uso de instrumentos técnicos capaces de incrementar su capacidad para realizar diagnósticos oportunos y adecuados (Salud Pública de México, vol. 45, nº 6, 11-12/2003).

Aunque con el tiempo, y, por supuesto, de una manera por completo impremeditada, Louis Cuchas se hizo pintor y alcanzó la fama, lo extraordinario en la novela de Simenon es haber centrado su indagación sobre lo que predispone a ser artista, que consiste primordialmente en una determinada forma de mirar, se convierta o no luego ésta en una profesión de más o menos éxito (El País. Babelia, 22/03/2003).

El especialista agrega que el método desarrollado por el CICY aprovecha las ventajas del estado, como son un clima propicio durante todo el año, sin riesgo de heladas, y primordialmente la disponibilidad de agua estimada anualmente en nueve mil millones de metros 
cúbicos (que terminan en el mar), a profundidades no mayores de 15 metros (Investigación y Desarrollo. Suplemento de Ciencia y Tecnología de La Jornada, 01/2003).

Pospuesto, con un adjetivo:

La camisa. Blanca o negra, primordialmente. Especialmente rabiosa resulta la combinación de ambos en unos - cuanto más ridículos mejor- lunares. Camisa blanca de Zara, 29,90 euros, y negra de Armand Basi, 54 euros (El País. El País de las Tentaciones, $09 / 05 / 2003)$.

En la siguiente aparece una aclaración restrictiva, lo que lo acerca al valor sobrerrealizante.

Ante ello y como una forma de contribuir a la minimización del impacto de la discapacidad - primordialmente neuromotora-, alumnos del Instituto Tecnológico de San Luis Potosí desarrollaron Triunfo, un sencillo y económico recogedor de objetos con apariencia similar a la de un brazo robótico que abre y cierra su mano, pero accionado de forma mecánica mediante una palanca y cables tensores, el cual sirve al discapacitado como una extensión de su propia mano que le permite realizar actividades con mayor independencia y seguridad (Investigación y Desarrollo. Suplemento de Ciencia y Tecnología de La Jornada, 01/2003).

\subsection{Esencialmente}

Este elemento, al igual que en esencia, aparece con el valor de: "en sus constituyentes esenciales", "por naturaleza", manteniendo su valor léxico en casos como:

Los procesos económicos llevados a cabo dentro de los límites del santuario son mediatizados por instituciones esencialmente no económicas, que abren espacios sociales, políticos y económicos fluidos. (Umbrales. Suplemento del diario Tiempo, 07/2003).

Es frecuente con atributos:

4. Reformar el artículo 332 (aprobado) eliminando el término pandilla como una forma de asociación ilícita, pues la misma es esencialmente un fenómeno social y no es necesariamente el equivalente a un grupo criminal (Tiempo, 05/01/2004).

A partir de aquí esencialmente (no en esencia) deriva a un uso en que privilegia un segmento sobre otros posibles de su paradigma, y lo enfatiza. Es semejante a sobre todo. Con en esencia se mantendría el valor circunstancial y su valor léxico. No llegaríamos al valor intensificador.

La forma de desplazar el punto de vista desde el receptor hasta el fenómeno comunicativo como un sistema global consiste, esencialmente, en analizar los datos que hemos obtenido en la investigación tomando como referencia central las variables vinculadas a las características del mensaje, en lugar de tomar las vinculadas a los receptores (Revista Telos, $01-03 / 2004, n^{\circ} 58$, Segunda Época). 
Aquí aparece entre pausas y pone de relieve el análisis de los datos por encima de otras cosas. Este es el contexto más habitual para el operador de preferencia. Pero otras veces aparece integrado en el grupo fónico del segmento al que afecta:

También el Centro Jovellanos, dependiente del Ministerio de Fomento, y las universidades de Alicante y Cádiz, cuentan con simuladores destinados esencialmente a la formación (Revista del Ministerio de Fomento, $\mathrm{n}^{\circ} 522,10 / 2003$ ).

En general, este tipo de leche se utiliza esencialmente para la fabricación de queso (A tu salud. Suplemento Salud de La Razón digital, 27/1 1-03/12/2003).

En estos casos aparece referido a un sintagma nominal complemento del verbo que se enfatiza. Debido a su valor léxico, cuando se emplea con adjetivos, se acerca al intensificador. En este contexto va antepuesto sin pausa:

Ambos procuraban explorar los valores espirituales de una cultura esencialmente pura, en su vínculo con la tradición cultural africana, una cultura magnética y viva, no contaminada para entonces (Revista Artes en Santo Domingo, Año 2, $\mathrm{n}^{\circ} 7,04-07 / 2003$ ).

De su producción esencialmente pensada, reflexionada y meditada como experiencia creativa basada en su visión de la cultura negra haitiana, están sus obras directamente referidas al Vodú y a numerosas deidades correspondientes al panteón animista de la religiosidad haitiana (Revista Artes en Santo Domingo, Año 2, no 7, 04-07/2003).

Los adjetivos están enfatizados, puestos de relieve informativamente:

El cargo de director del comité se creó hace poco para fortalecer un órgano que hasta ahora había cumplido un papel esencialmente simbólico, informa desde Nueva York Isabel Piquer (El País, 01/04/2004).

Aunque la cumbre tiene una agenda esencialmente económica, la delegación cubana al evento quiere buscar un pronunciamiento de solidaridad frente a las recientes medidas adoptadas por el presidente estadounidense George W. Bush (El Nuevo Herald, 24/05/2004).

La subversión que nos propone Jackass es civil, escatológica y esencialmente lúdica (La Luna del siglo XXI, 14/02/2003).

\subsection{Principalmente}

Este adverbio presenta un comportamiento más complejo:

a) Por su base léxica (principio) tiene un valor de posición adelantada, que lo relaciona con otros, como antes que nada, ante todo, marcadores también de punto de inicio. Este valor puede dejarse notar en un caso en que el hablante va a exponer varias razones y parece utilizar el elemento como ordenador de su exposición. Su posición en la oración no sería compatible con sobre todo.

La pregunta es ¿por qué el Manga y el Anime son tan famosos entre los jóvenes y adultos jóvenes a nivel mundial? La respuesta quizás sea muy extensa, pero hay algunos puntos básicos para explicar por qué el Anime llega a enamorar al público.

Principalmente para muchos expertos el uso dentro del Manga y el Anime de diversos perfiles psicológicos para los personajes, los que se mantienen a lo largo de la historia, y 
la reacción de estos ante los problemas que se les presentan, logran hacer del espectador casi protagonista, ya que generalmente el joven se siente identificado sin importar si es el personaje principal o solo un personaje secundario Además es usual que el protagonismo se llegue a centralizar en más de un personaje, lo que permite cautivar a más público (Art Studio Magazine, 6, 2-3/2004).

No es exactamente un conector, pero su valor se acerca al de un ordenador como ante todo.

b) Puede aparecer, como especialmente, manteniendo su valor léxico de adverbio de modo. En estos casos modifica a un verbo o participio, calificando la acción verbal:

La decoración del living es muy simple, conformada principalmente por un par de sofás y dos baúles que sirven como mesa de centro (Vivienda y Decoración. Suplemento del diario El Mercurio, 31/01/2004).

Equivale a "en lo principal" y en este contexto no puede ser sustituido por sobre todo. Tampoco en el siguiente, semejante a un modificador de un adjetivo, posición que no ocuparía sobre todo:

Tiene varias etapas y se va cumpliendo año por año. Por ejemplo, el 2002 fue el año del relanzamiento de Cristal. En 2001 se buscaron nuevas ocasiones de consumo, ese año se lanzó Lemon Stone principalmente dirigido a la mujer (El Mercurio, 06/02/2004).

Además, la comida ya representa un $30 \%$ de los ingresos del sector, cifra que debería seguir creciendo gracias a un aumento de la oferta de platos preparados, que son principalmente apetecidos por profesionales solteros que viven solos (E1 Mercurio, 06/02/2004).

Principalmente establece como foco el adjetivo. Sobre todo, si apareciera, iría pospuesto y focalizado sobre la relación: "dirigido a la mujer", "apetecidos por profesionales". Desplazaría el alcance de su acción.

c) Como operador de preferencia, privilegia a unos miembros entre un grupo:

CCOO teme que en la operación exista principalmente un trasfondo inmobiliario (Diario de Jerez Digital, 27-1-2004.

En este caso aparece sin pausa, antecediendo al segmento al que afecta y enfatizándolo informativamente.

Aparece también introduciendo una restricción, un elemento menos extenso en una estructura de reinterpretación. Encontramos algún caso al inicio de enunciado, como continuación del anterior:

Con esto no pretendo desprestigiar la noble labor que realiza o hemos realizado todo el personal de Salud en Nicaragua. Porque, precisamente, somos los estudiantes de medicina, enfermeria y técnicos de laboratorio — durante el año de servicio social-, la principal esperanza para mitigar las múltiples dolencias fisicas y mentales de nuestra población. Principalmente de aquellas personas que viven en las zonas más alejadas y menos favorecidas de nuestro país, en condiciones muchas veces inimaginables para los que residimos en la capital (Campus de Nicaragua. Suplemento de Tiempos del Mundo digital 26, 26/6$2 / 7 / 2003)$. 
Añade una circunstancia que restringe la extensión de lo dicho en el enunciado precedente:

¿Por qué hay más mujeres que hombres en la UASD? En los mercados de trabajo metropolitanos la inserción femenina es más intensa que la masculina. Principalmente en el sector de servicios y educación la mujer lleva la delantera (Revista Ahora, 26-5-2003).

También puede introducir una causa, o justificación de lo dicho:

Acabado el sueño, caída la ilusión de transparencia y solidez del canon cinematográfico, vencidas las reglas del juego, lo que queda parece un páramo insondable que no sabemos con qué llenar. Sin embargo, esta nueva amenaza, ni es tan nueva ni es tan amenazante. Principalmente, porque esta capacidad en decadencia que posee el cine para crear simulacros ha ido desde siempre de la mano de otra capacidad, no tan degradada, que es la de poner en entredicho esa realidad a través de su perspectiva múltiple (Film (on line) 6-7/2003).

Estamos en un caso de reinterpretación argumentativa. Añadimos los argumentos de lo dicho, información seleccionada y considerada más importante por el hablante. Marcos argumentativos, que restringen la aplicación de lo dicho al contexto más relevante.

Puede aparecer, como vemos, con pausa o sin ella.

d) En otros casos no parece fácil la sustitución por sobre todo. Y se coloca en posición final, pospuesto al sintagma que constituye su ámbito.

Una de las grandes falacias de la ideología neoliberal de la globalización consiste en propagar a los cuatro vientos la progresiva desaparición del Estado y de sus costosas e ineficaces burocracias públicas y, consiguientemente, la consolidación de la supremacía del mercado sobre los Estados y del sector privado sobre el sector público. Esto lleva implícita una degradación de las decisiones políticas y sociales de los Estados en favor de las decisiones económicas y financieras de los nuevos poderes difusos de carácter supraestatal de las grandes empresas transnacionales y de las organizaciones económicas internacionales, como el Fondo Monetario Internacional o la Organización Mundial del Comercio, principalmente. Pero, en realidad, esta afirmación es, simple y llanamente, una falsedad (El Diario Vasco, 23-1-2004).

PERSONALIDAD y PERSONERÍA. Se ha observado que con suma frecuencia, tanto en algunos medios de comunicación como en declaraciones de funcionarios públicos y personajes políticos principalmente, se emplee la palabra personería con el significado de personalidad. Sus significaciones son absolutamente diferentes (La Prensa Literaria. Suplemento semanal del diario La Prensa, 01/05/2004).

Parece estar cercano de una estructura de concreción o explicación. Sigue a un elemento general, pero más que introducir una circunstancia, muestra un caso especifico:

El $66 \%$ de los españoles ve inconvenientes en el euro, principalmente la subida de precios (20 Minutos. Madrid, 14/01/2004).

Con el mismo valor lo encontramos en incisos:

Los letreros que indican las calles en San Sebastián carecen de uniformidad. Las placas, colocadas sobre las fachadas de los edificios, presentan colores diferentes (principalmente 
azul o blanco), están fabricadas con materiales distintos (cerámica o metal) y su diseño es diverso, desde formas rectangulares a ovaladas (El Diario Vasco, 23/01/2004).

Es semejante a un conector de concreción y ejemplificación, marcando cierta fuerza argumentativa o escala entre sus miembros.

\subsection{Fundamentalmente}

Este operador presenta varios contextos de aparición. L. Santos Río recoge un valor oracional, como adverbio de referencia o enmarcador, un valor aspectivo ("en lo fundamental") y otro en que modifica a adjetivos "y muy en particular a los que remiten al carácter o índole de las cosas así como a las locuciones adjetivales correspondientes: "Razones fundamentalmente económicas(...)" (L. Santos Río: 1994, 124). Veamos sus empleos.

En primer lugar, puede actuar como un modificador del verbo: "en lo fundamental", manteniendo su contenido léxico originario, en:

Se trata de un trabajo dirigido fundamentalmente a los alumnos extranjeros que, en dicho centro, representan al $14 \%$ de la población escolar (El Periódico Mediterráneo, 21/05/2004).

Parece cercano ya al valor de preferencia. En el siguiente se percibe de forma más clara:

Oro del Perú, que ha sido comisariada por la arqueóloga Gabriella Schwörbel, reúne piezas trabajadas fundamentalmente en oro, aunque las hay también combinadas con plata, platino, bronce y piedras preciosas (El País. Babelia, 24/04/2004).

El siguiente es un contexto muy frecuente:

El DCA constituye en la actualidad uno de los problemas de salud pública más importantes y como tal debe ser considerado. Las cifras del DCA, especialmente el postraumático, han experimentado un espectacular crecimiento debido fundamentalmente a la elevada siniestralidad vial (Medicina y Salud. Suplemento del diario Información, 14/02/2004).

Va siguiendo al participio. Incluso con "debido", cercano a la gramaticalización como partícula causal: debido a. Aquí interponemos el adverbio para modificar la acción verbal expresada en el participio.

La incorporación de esta instancia clasificatoria de la música construye relaciones con las músicas de la región y los países del MERCOSUR en el contexto de un proceso de "integración" y regionalización por el momento fundamentalmente atendido en su dimensión económica, pero que de hecho implica el inicio de dinámicas de redefinición de lo propio, de lo local (Revista Telos, 01-03/2004, $\mathrm{n}^{\circ}$ 58, Segunda).

El valor de preferencia, semejante a sobre todo, se ve claramente mostrado cuando aparece pospuesto con pausa. 
Tiene un valor claro de potenciación argumentativa de un segmento. El paradigma aparece implícito.

En la siguiente aparece con otro adverbio cercano significativamente a él básicamente:

Manuel Palacio / Juan Carlos Ibáñez (M.P./J.C.I.): Desde la perspectiva que proporciona un recorrido amplio, que sobrepasa los cuarenta años de intensa actividad científica y ensayística, y aunque suene a pregunta tópica, ¿cómo se auto-definiría Román Gubern?

Román Gubern (R.G.): Básicamente me siento historiador. Soy atípico, porque he tocado muchas teclas - -he publicado treinta y tantos libros-, pero mi forma de pensar preferente, de afrontar problemas, es fundamentalmente la de un historiador (Revista Telos, 01-03/2004, n 58, Segunda Época).

Opera también en estructuras restrictivas, como sobre todo:

Los efectos tóxicos de este metal pueden causar daños en la salud, fundamentalmente en los niños puesto que ellos "lo eliminan peor, mientras que el adulto tiene mayor capacidad para expulsarlo a través de la orina", explica el doctor Lluis Serra, Presidente de la Sociedad Española de Nutrición Comunitaria (La Razón, 24/03/2004).

Valor puramente de relieve informativo, sin más, parece tener en el siguiente caso:

Sus experiencias son hoy motivo de atención para los alumnos de Inacap con quienes comparte, fundamentalmente, las razones que lo han llevado a persistir en esta larga y peligrosa carrera (Por fin viernes, suplemento de La Segunda, 12-3-2004).

En este contexto parece alejarse de sobre todo. Y también es muy frecuente afectando a toda la oración, con esa función de preferencia informativa:

José Luis de la Herrán es egresado de la escuela de ingeniería de la Universidad Nacional Autónoma de México. Fundamentalmente es experimentador, constructor y adaptador de tecnologías, así como impulsor de la educación científica (Revista Digital Universitaria 4, 1, 3-2003).

"Lo cual, admite Saramago, tampoco implica un cambio de sistema. ¿Por qué? Que sea el Nobel quien lo explique: "El poder real está en otro lado. Fundamentalmente en el poder económico, que como todos sabemos no es democrático" (La Prensa Literaria, Suplemento semanal del Diario La Prensa, 1-5-2004).

En el siguiente parece cercano a la enunciación:

P: Gran Hermano y ese tipo de programas voyeuristas ¿son hermanos bastardos del documental?

R. Ya quisieran serlo. Fundamentalmente me parecen aburridos: eso sí que anestesia (El Mundo, Magazine, 16-3-2003).

¿Qué trámites supone este cambio de titular? Fundamentalmente, obliga a inscribir las modificaciones antes descritas en el Registro de la Propiedad (El Mundo. Su vivienda (suplemento) 17-1-2003).

Equivale a "lo que quiero decir es sobre todo lo siguiente". Afecta a todo el decir y resalta toda la información que continúa. Deja, pues, el valor argumentativo y actúa solo como operador informativo. 
Sobre todo establece los elementos en una escala y habla de una superioridad que parece basarse en la posición (de ahí el valor situacional de sobre). En el caso de fundamentalmente las razones de la preferencia están en una jerarquía que atiende a lo básico o fundamental frente a otros aspectos menos importantes. Fundamentalmente equivale a "diciendo lo más importante, lo básico". Y está más cerca de principalmente. En algún caso parece haber derivado a la mera enfatización informativa y se acerca a lo enunciativo. Enunciación, enfatización, argumentación e intensificación se unen, pues, en este elemento.

\subsection{Básicamente}

Relacionado con los dos anteriores, fundamentalmente, principalmente, este adverbio también indica ir a lo más importante, concretamente a lo que está en la base (fundamento, principio, en los otros).

L. Santos Río considera para él dos usos: el enmarcador o de preferencia, y el aspectivo. Nosotros organizamos sus empleos del siguiente modo:

1) Puede usarse como un complemento limitativo o de punto de vista. Incluso en este sentido se puede acercar a lo enunciativo: "diciendo lo básico, hablando básicamente".

Según las fuentes consultadas por el periódico, la propuesta consiste básicamente en modificar el tope máximo o "cap" de militares estadounidenses con autorización para permanecer en Colombia (El Universal, 23/03/2004).

La estrategia comunicativa del programa es básicamente una estrategia comercial (Revista Telos, 01-03/2004, n⿳0 58, Segunda Época).

Los departamentos femeninos se diferencian básicamente por los colores de las prendas y por la luz más focalizada que a éstas les llega (Vivienda y Decoración. Suplemento del diario El Mercurio, 31/01/2004).

Como podemos observar, es un empleo que no está tan lejos del valor de preferencia. A veces resulta difícil establecer el límite entre ellos, como ha ocurrido en estos últimos ejemplos citados.

2) Como marcador de preferencia, equivalente a sobre todo, lo encontramos enfatizando un segmento:

Además de garantizar una audiencia fiel y, por ende, un beneficio económico para la televisión, toda vez que los medios se financian básicamente vendiendo audiencias a los anunciantes (Revista Telos, 01-03/2004, n ${ }^{0} 58$, Segunda).

Se combina también con adjetivos. Pero no adopta valor intensificador:

Las causas para este lento crecimiento en Europa, y por ende en España, son básicamente económicas (El País, 01/04/2004).

La Orquesta Arturo Toscanini es un excelente conjunto que cubre la actividad musical en la región de Emilia Romagna, cuyos componentes, básicamente jóvenes, siguieron con entusiasmo las órdenes de la batuta (La Razón, 24/03/2004).

Más bien parece que Blair quiere entregar a las escuelas un instrumento básicamente disuasorio, que obligue a los alumnos a darse cuenta de que si consumen drogas pueden acabar siendo descubiertos en la escuela (El País, 23/02/2004). 
Puede intercalarse entre un núcleo y su modificador.

Como bien explica la periodista científica norteamericana Dava Sobel en su excelente obra Longitud (1995), los cartógrafos que le sucedieron trasladaron esta línea a diferentes lugares o ciudades, en función, básicamente, de la hegemonía políticoeconómica de un país u otro (El País. Ciberpaís, 08/01/2004).

Tanto él como Pradillo tendrán la capacidad de llevar las riendas del suburbano, es decir, que básicamente lo que ayer se creó es una bicefalia en la dirección (La Razón digital, 22/04/2004).

Aparece también con participios.

Antes de la firma del nuevo acuerdo, el CSN y AERO tenían una estrecha relación centrada básicamente en la licencia emitida por el primero a los profesionales sanitarios que dirigen y administran tratamientos radioterápicos sin la cual no pueden realizar esa labor (A tu salud. Suplemento Salud de La Razón digital, 11-17/03/2004).

Registramos un empleo en que afecta a toda la oración. Aparece en este caso en posición inicial con pausa y se refiere a la enunciación. Enfatiza todo lo dicho.
¿Abordaría un tema serio?
No, me da pereza. Pero me encantaria hacer un musical.
Tiene pinta de pasar olímpicamente de la crítica...
Básicamente, le doy la importancia que tiene, la opinión de un solo individuo (muchas veces altamente cualificado, eso si) (20 minutos, Sevilla, 19-1-2004).

En ninguno de estos casos la preferencia tiene un efecto de sobrerrealización argumentativa. Es un focalizador informativo, pero no aporta más fuerza a lo dicho. No aparece en estructuras de reinterpretación restrictiva. Esto lo hace alejarse de sobre todo. Por el contrario, aparece en un contexto como operador informativo de toda una enunciación, contexto en que sobre todo parecería extraño.

\subsection{Especialmente, en especial}

Estos dos elementos, del mismo origen y paralelos en su significado, confluyen en su comportamiento como operadores de preferencia, aunque también tienen otros contextos de aparición, en los que no coinciden.

Especialmente es un adverbio que precede a un elemento y adopta diversas funciones:

1) Adverbio de modo: "de modo especial", principalmente con verbos o participios. Califica la acción verbal.

Terminó inventando sábados completos de show, con obras de teatro en que actuábamos nosotros; con Benito Orellana, un mago que traía especialmente contratado" (Vivienda y Decoración. Suplemento del diario El Mercurio, 31/01/2004).

Para esta versión, el argentino dice haberse entrenado especialmente para enfrentar los declives. Por lo mismo, se espera que no aparezca tan seguido en los embalajes (El Mercurio, 08/03/2004). 
2) Operador intensificador: Aparece con adjetivos evaluativos. Sin pausa. Generalmente antepuesto, en algún caso pospuesto. Proporciona énfasis informativo al adjetivo y se centra en la enunciación del hablante.

Detrás del éxodo están la burocracia europea, especialmente fatigosa en Alemania y Francia, las rígidas jerarquías imperantes en el viejo continente, la frustrante dispersión de mentes brillantes y la escasa inversión de organismos públicos y entidades privadas (20 minutos. Sevilla, 19/01/2004).

La inculpación de Bédier, que ya tuvo que renunciar como candidato a la presidencia de la región de París en las listas del partido conservador en el poder, UMP, por sus problemas judiciales, resulta especialmente delicada dado su cargo como responsable de las prisiones francesas (El Diario Vasco, 23/01/2004).

Puede aparecer al inicio de la frase seguido de un adjetivo, proporcionando un mayor relieve informativo.

Especialmente significativo es el contraste del caso español con Portugal, único Estado de los citados que tampoco cuenta con la subvención vía canon por hogar (Revista Telos, $1-3,2004, n^{\circ} 58$ ).

Pero en estos valores no podemos olvidar el efecto intensificador que adopta. No es claramente un cuantificador, pero está cercano a él. Equivaldría a "muy significativo", "significativo en un grado considerado especial"":

Especialmente desconcertante a este respecto resulta el libro No haya corrupción (El País, Babelia, 24-4-2004).

La gripe llegó este año pronto y adelantó algunos de los problemas que siguen a este brote, pero perdió intensidad a finales de noviembre y no fue especialmente virulenta (El Diario Vasco, 23/01/2004).

Puede aparecer también negado, como podemos comprobar, a diferencia de la mayoría de los otros operadores considerados, con la excepción de particularmente.

3) Operador de preferencia. Equivale a sobre todo, y a en especial. Establece el relieve de un elemento.

El exotismo funciona especialmente como avidez de "otredad" (Revista Telos, 01-03/2004, $n^{\circ} 58$, Segunda Época).

Aparece a veces en la estructura "general+ especialmente, elemento concreto", contexto restrictivo específico de los operadores de preferencia. Pone de relieve un miembro del paradigma, y presupone otros. Generalmente es un aditamento de tiempo, modo, causa... Pero también un sujeto, un complemento indirecto...

El informe parlamentario, elaborado por el eurodiputado gallego Daniel Varela (Grupo Popular), propone a la Comisión Europea y a los Estados miembros que pongan en marcha 
una serie de medidas de orden comercial y estructural, a la vez que pide expresamente al departamento de Pesca, que dirige el comisario Franz Fischler, que elabore un plan específico para el sector, un marco de apoyo estructural y un plan de defensa frente a la competencia supuestamente desieal de las importaciones procedentes de países terceros, especialmente del sudeste asiático (La Voz de Galicia, 15/01/2004).

Puede incluso ir modificado por muy, combinatoria común a particularmente. No la encontramos con los otros: *muy fundamentalmente, *muy esencialmente, *muy básicamente:

En ella indaga en el poder transformador de la literatura, muy especialmente en el de la lectura, "una forma de viajar, y a veces una experiencia tan íntima equiparable sólo al enamoramiento" (El Universal, 23/03/2004).

En todos ellos introduce un sobrerrealizante, un elemento que aporta mayor fuerza a lo dicho: "indaga en el campo de la lectura más que en los demás". Este campo se sobrepotencia. Lo encontramos también en un inciso aclarativo:

Si Bush, Blair y Aznar no actuaron equivocados, creyendo de buena fe que se encontraban ante una emergencia vital; si sólo actuaron, especialmente el primero, para asegurar a su país una posición de ventaja en el mercado petrolífero, su conducta sería delictiva y estaría ayuna de cualquier justificación exculpatoria (El País, 01/04/2004).

Incluso constituyendo un enunciado completo:

Pero como ante el Zaragoza, jugar mejor no significa ganar, ni mucho menos. Al Betis le sigue faltando gol. Y de eso, el Real Madrid anda sobrado. Especialmente Ronaldo (20 minutos, Sevilla, 19-1-2004).

Al inicio del enunciado se utiliza como procedimiento de relieve:

Especialmente en el caso de Iraq se barajaba que el personal sanitario tuviera que atender a nuestros propios soldados... (A tu salud, suplemento salud de la Razón digital, 13-19/ $5 / 2004)$.

Especialmente porque es un espacio compartido entre muchos investigadores, las medidas de seguridad planificadas de la UEG se corresponden con las empleadas en laboratorios internacionales de biología molecular (BIS: Boletín informativo Semanal del Ministerio de Ciencia y Tecnología de Venezuela, 8-1-2004).

En especial sólo presenta el último contexto, el de operador de preferencia. Equivale a "sobre todo", y como él, aparece en estructuras restrictivas. La mayoría de las veces se antepone, aunque también hemos encontrado dos casos pospuestos. Los adjetivos con los que se combina son relacionales.

A criterio de la psicóloga clínica Sonia Melville, en la medida que el niño conozca uno o más idiomas se le facilitará la comunicación con el mundo, en especial en esta era de la globalización y el Internet (Prensa Libre, 27/05/2004).

Sin embargo, consulte siempre con su médico antes de empezar cualquier clase de ejercicio, en especial durante el embarazo (Hoy Digital. Suplemento Salud, 31/03/2004). 
Puede ir en un inciso:

La Universidad Mayor de San Andrés, en especial la Carrera de Derecho, seguramente seguirá patrocinando cursos, congresos y eventos que eleven el nivel de formación en la materia y no sólo de la Medicina Legal sino de todas las ramas de las Ciencias Forenses (La Medicina en tus Manos. Suplemento de El Diario, 06/02/2004).

El presidente de la Diputación gaditana explicó que esta distinción —anunciada en este medio en su edición del pasado viernes - tiene su origen tanto en la labor realizada desde hace años por Chamizo en favor de los más desfavorecidos de la sociedad - en especial los drogodependientes-- como en la vinculación y la defensa de Cádiz que ha mantenido en su nuevo puesto como Defensor del Pueblo Andaluz (Diario de Jerez Digital, 27/01/2004).

Todos ellos, como vemos, responden al valor del operador de preferencia que actúa como sobrerrealizante, elemento de potenciación argumentativa.

A veces con $y$ :

Esta demanda del Ecofin toma especial relevancia ante la fuerte revalorización de la divisa europea frente al dólar, situación que afecta negativamente al comercio internacional y, en especial, a las exportaciones europeas (Estrella Digital. El primer diario electrónico en español, 21/01/2004, n 2009, año VII).

Puede introducir un segmento y ocupar todo el enunciado:

"Queremos agradecer al personal del Hospital Doctor Ernesto Torres, por la excelente atención que recibió mi padre Francisco González Miranda (QEPD), quien sufrió de un cáncer terminal. En especial a los doctores Claudio Pinto, Palacios, Gonzalo Montalvo y su secretaria y enfermera, además a la secretaria del Some, Norma Varas" (La Estrella de Iquique, $\left.\mathrm{n}^{\mathrm{o}} 12.516,16-3-2004\right)$.

Cuando se pospone, pierde este valor argumentativo. En este caso mantiene su valor léxico, en correlación con en general:

"Para los dolores de espalda en general y lumbalgias y tortícolis en especial, es también una de las técnicas más recomendadas, llegando a tener "efectos casi inmediatos: con 2 ó 3 sesiones se solucionan', apunta Palacios" (A tu salud, Suplemento Salud de la Razón digital, 15-21/1/2004).

\subsection{En particular- particularmente}

Otros elementos cercanos son particularmente y la expresión en particular, con los que ha sido relacionado sobre todo en la bibliografia (Así J.L.Anscombre: 2001).

En particular tiene varias funciones:

1) Mantiene su valor léxico como complemento circunstancial, en relación con en general (explícito o implícito), valor muy semejante al de concreción:

Tratándose de la "libertad de expresión" y de una facultad en la que la comunicación en general, y el periodismo en particular, constituyen el eje de sus enseñanzas, no es 
necesario invocar ningún motivo especial para justificar la selección de este tema para celebrar conjuntamente ambos aniversarios. Pero vivimos tiempos curiosos en los que la mentalidad (Revista Telos, 01-03/2004, $n^{\circ} 58$, Segunda Época).

De la misma forma es partidario de invertir recursos en toda la comuna, sin privilegiar a ningún sector en particular (La Estrella de Iquique, $n^{\circ} 12.516,16 / 03 / 2004$ ).

En su cara se dibuja la alegría del buen momento del equipo y el suyo en particular (El Mercurio, 08/03/2004).

Un uso que entra dentro del valor léxico, pero que puede acercarse a lo enunciativo es el que lo hace equivaler a personalmente. Pero en ocasiones no se refiere al hablante, por lo que está más cercano a en persona, en concreto.

En efecto, cada lector de la Biblia ha de encontrar su interpretación, es decir, aquella que le está destinada a él en particular; ha de saber extraer su sentido, es decir, el sentido que corresponde a su situación personal (Revista Femenina. Suplemento de El Diario, 15/04/2004).

Para Benavent, no es casual que cada vez que se acercan las elecciones "ella comienza con su martilleo contra el PSOE: es como el famoso turrón que vuelve a casa por Navidad, y no sé si lo hace animada por alguien en particular, pero cuando hay elecciones sale siempre con su historia" (Diario de Jerez Digital, 27/01/2004).

En todos estos empleos aparece pospuesto sin pausa, formando parte del grupo fónico del elemento al que afecta.

2) Funciona como operador de concreción, en una estructura general-particular, valor también derivado de su base léxica:

$\mathrm{Si}$, como yo, son admiradores de Mafalda, sabrán de qué les voy a hablar, pues se trata de lo que más odiaba esa encantandora niña salida del lápiz del genial Quino. Asi es, voy a hablarles de la sopa. En particular, de por qué soplamos sobre ella para que se enfrie (20 minutos, Sevilla, 19-1-2004).

"Demasiada invención, demasiada maldad, demasiada perversión como para ser ni siquiera verosímil, pero los lectores más inocentes pueden quedarse con la idea de que la Iglesia Católica, y en particular el Vaticano y el Opus Dei, es una institución poco fiable", este es el extracto del artículo Bestseller tramposo, incluido en la página española del Opus Dei (El País. Ciberpaís, 22/01/2004).

3) Como operador de preferencia es frecuente antecediendo a un sintagma complemento:

Z.- ZZZZZ.... Duerma... Asegúrese de descansar bien... Es aconsejable acostarse de lado lo más a menudo posible, en particular sobre el lado izquierdo, porque esa posición permite una mejor circulación para su bebé y ayuda a reducir la hinchazón (Hoy Digital. Suplemento Salud, 31/03/2004).

Admite la intensificación con muy, como especialmente:

Carta blanca narra la historia de Juan Faura, joven de buena educación a quien un desengaño amoroso le empuja a alistarse en la Legión. Como legionario, Faura combate en la guerra del Rif, y entre las muchas atrocidades que le toca allí vivir, lo marca muy en 
particular una razia nocturna en la que participa todo su pelotón y en la que se cometen todo tipo de crueldades (El País. Babelia, 24/04/2004).

Valor de restricción, introduciendo una reinterpretación, mantiene en el caso siguiente:

Explicó que las mejoras en este campo se extienden por varios territorios. Sobresalen las labores de drenaje en el pueblo de Jagüey Grande, lugar donde las inundaciones son memorables, en particular en el barrio de Cantarrana (Granma, 25/05/2004).

Puede llegar incluso a comportarse como un operador de relieve informativo, sin otro valor:

La unidad se encargará en particular de controlar los posibles daños a árboles y vegetales de la ciudad, las construcciones ilegales en terreno municipal, las personas que no acuden a los sitios previstos para que sus animales defequen, las pinturas ilegales en mobiliario urbano, el depósito de residuos en lugares y a horas inadecuados y el descuido en los lugares peligrosos, en particular en caso de riesgos de incendios (El Periódico Extremadura, 06/05/2004).

El primer ejemplo contrasta claramente con el segundo caso, que es el de preferencia: ahí podemos sustituirlo por sobre todo. Añade un complemento, una restricción.

Puede incluso combinarse con sobre todo, en una escala de restricción. Aunque es un caso ambiguo, que también podría interpretarse como un uso de en particular como marcador de concreción.

En inglés añadió que el FMI "concentrará sus esfuerzos en dirección a los países que demandan ayuda técnica y financiera y los programas del Fondo, sobre todo los países menos desarrollados y, en particular, los países africanos" (El Periódico Extremadura, 06/05/2004).

Particularmente ha sido estudiado por J. C.Anscombre (2001), en conexión con surtout. Para él tiene dos valores:

1) Un valor intensificador, de grado, con adjetivo, verbo o adverbio. Distinto a sobre todo.

2) Un valor "surenchérissseur" (sobrerrealizante): Adverbio restrictivo. Equivale a sobre todo, especialmente, esencialmente, singularmente.

No cita el valor de "en persona", pero reconoce un contexto que llama "descalificador": "Q(conclusión): P1, (y) particularmente P2". En esta estructura particularmente descalifica los argumentos de tipo P1 diciendo que sólo P2 cuenta.

En mi opinión, particularmente abarca las siguientes funciones:

1) Puede mantener su contenido léxico e indicar "de una forma particular o especial". Es un modificador de modo, generalmente del verbo. 
"Es la clase de método que solía utilizar la CIA", dijo Bigwood. "Yo no estoy interesado particularmente en el Sr. Chávez, sino que estoy interesado en lo que Washington está haciendo" (El Mundo, 18/03/2004).

"No queremos cuestionar el hecho de que Francia recaude una tasa de las entradas de cine y los DVD", incluidos los estadounidenses, para financiar la producción francesa, pero "tampoco dije que lo apreciemos particularmente" añadió Valenti, quien subrayó haber firmado acuerdos de libre intercambio en el terreno audiovisual con Chile, Singapur y Australia (La Razón, 24/03/2004).

Pero incluso este mismo caso puede interpretarse con el valor de personalmente, cercano a lo enunciativo. Así también lo vemos en los siguientes:

Particularmente los zulianos se dieron el lujo de arrebatarle el invicto al líder Marinos, acrecentando aun más la rivalidad entre oriente y occidental (El Universal, 23-3-2004).

En este caso modifica al sujeto y equivale a especialmente, o a personalmente. En otros casos alude o implica al sujeto hablante:

Podría objetarse que las personas a veces aplican sus propias reglas. Pero aplicar "reglas propias" es equivalente a no aplicar reglas sociales, a menos que esas reglas propias sean añadidas particularmente por nosotros a la observancia previa de las reglas sociales (Revista Telos, 01-03/2004, n 58, Segunda).

"Cántico" plantea esta cuestión de fondo, que particularmente es la que más me sigue sorprendiendo (San Juan de la Cruz, n 31-32, 01-02/2003).

Apunta al locutor. Es una marca clara de él. Expresa una opinión.

2) Como en particular, puede actuar como un operador de concreción, aunque este es un contexto menos frecuente:

Un dato que parece apoyar lo anterior consiste en que en un hospital general casi la cuarta parte de la población intrahospitalaria recibió psicofármacos, particularmente benzodiazepinas, siendo que únicamente $8.59 \%$ de esos pacientes tenían un diagnóstico psiquiátrico (Salud Pública de México, vol. 45, nº 6, 11-12/2003).

3) Con un adjetivo, actúa como intensificador. Es un focalizador, pero no de preferencia. Equivalente a especialmente, añade a la enfatización un contenido semántico calificativo:

Particularmente interesante es el análisis resultante de las visitas realizadas a sitios de la competencia, con miras a visualizar el tratamiento que da a la utilización de bases de datos; la simplicidad /complejidad de sus sistemas de navegación, o el carácter eminentemente informativo o transaccional que tengan (Revista Digital Universitaria, 4, 1, 2003).

"Particularmente interesante" se entiende como "interesante en un grado alto y especial frente a otros".

Esto, por cuanto se formularon en medio del proceso de fijación de tarifas que afecta a los operadores del sector de telecomunicaciones y de servicios sanitarios de mayor tamaño del país, el cual aún no finaliza y ha sido particularmente conflictivo en el pasado (El Mercurio, 08/03/2004). 
Su distribución es, como estamos viendo, antepuesta al adjetivo y muchas veces al inicio de enunciado, para potenciar el relieve informativo.

El 15 de marzo, se realizan masivas manifestaciones contra la guerra, en todo el mundo, siendo particularmente masivas, con más de un millón de personas, las de Londres, Madrid, Roma y Barcelona (El Socialista, $n^{\circ} 651,04 / 2003$ ).

Particularmente fascinante es el catálogo dedicado al arte tribal que Breton coleccionó desde que era estudiante, con piezas maravillosas de arte africano, oceánico e indio americano, algunas de las cuales pueden verse en fotografias tomadas por el propio Breton y que oscilan entre los 200 y los 700.000 euros (El Cultural, 7-4-2003).

Su valor intensificador (particularmente fascinante/muy fascinante) no es una cuantificación según una escala lógica o evaluable objetivamente, sino relativa. En la mayoría de los casos va con el verbo ser, con atributos. Puede incluso aparecer con negación: "no particularmente fascinante".

4) Funciona como marcador de preferencia, semejante a sobre todo, en los siguientes casos:

Zamora editó en 1909 un Album de Vistas de Costa Rica, lujosamente editado, donde 100 fotografias de diferentes lugares del país, paisajes, fotografía urbana y otros reflejaban su trabajo de años. Su obra se reconoce particularmente por la intervención y el retoque que realizaba a sus fotografias y retratos (Art Studio Magazine, $n^{\circ}$ 6, 02-03/2004).

También aparece en construcciones restrictivas general- particular:

Entre los desafios planteados por los organizadores del workshop se encuentra, en el nivel académico, motivar a más estudiantes a seguir la senda de la matemática aplicada, particularmente en el análisis numérico (Panorama en Internet, $\mathrm{n}^{\circ} 509,16 / 01 / 2004$ ).

Los reservorios originales de los virus gripales serian las aves, particularmente las acuáticas, desde las que se podrían difundir a otras aves de corral y a los mamíferos como el cerdo y los humanos, si se produjeran cepas capaces de infectarlos (El País. Salud, 02/03/2004).

Admite la anteposición de muy también:

Favoreceremos la cultura emprendedora, muy particularmente de los jóvenes, con el objeto de propiciar el autoempleo (El Socialista, $\mathrm{n}^{\circ}$ 651, 04/2003).

Incluso se coordina a elemento, en una escala de fuerza argumentativa:

La situación del sector del automóvil en Europa, y de General Motors muy particularmente, es de una rentabilidad "pobrisima o nula, y en estas circunstancias todas las marcas están tomando sus decisiones de inversión basadas en factores de coste laboral, productividad, calidad y flexibilidad productiva (El Periódico de Aragón, 14/05/2004).

Deben abstenerse aquellos que tengan sobrepeso o que sean obesos y particularmente aquellos aquejados de algún trastorno hepático, sobre todo en la formación y secreción de bilis. La bilis es una especie de detergente (Revista Nutrición XXI, nº 9, 01-02/2003).

$Y$ en enunciados parentéticos:

Entre estos últimos se encontró que las mujeres (particularmente en Pucallpa) tenían un mayor conocimiento de MAC que los hombres $(45.92 \%$ mujeres vs. $35.29 \%$ hombres) (Salud Pública de México, vol, 45, nº 6, 11-12/2003). 
En todos estos casos el relieve entonativo acompaña al valor sobrerrealizante, a la fuerza argumentativa.

\section{Conclusión}

Estos adverbios son elementos que:

- Tienen un alcance sobre un sintagma o, incluso, la oración.

- Focalizan su contenido: enfatización informativa.

- Suponen una selección por parte del hablante de ese elemento en contraposición con otros en una escala: Preferencia argumentativa.

- Son paradigmatizantes, es decir, presuponen un paradigma de elementos del que destacan o eligen uno, situado en posición preferente.

- Cuando actúan como operadores de preferencia pueden indicar meramente eso o bien marcar una potenciación argumentativa, una mayor fuerza, una sobrerrealización. Esto es más frecuente en las estructuras de reinterpretación.

Sus contextos de empleo son:

- Como circunstanciales de modo, manteniendo su valor léxico

- Como operadores de preferencia: — enfatizando un segmento

— como restrictivo, en la estructura general, ... particular

- Algunos actúan como intensificadores con adjetivos.

Aparte, pueden presentar otras opciones: limitativos como básicamente, en particular, enunciativos como particularmente, etc.. Veámoslo en un cuadro:

\begin{tabular}{|l|l|l|l|}
\hline \multicolumn{1}{|c|}{$\begin{array}{c}\text { Valor léxico No } \\
\text { gramaticalizado }\end{array}$} & Operador Preferencia & $\begin{array}{c}\text { Operador } \\
\text { Intensificación cualidad }\end{array}$ & \multicolumn{1}{c|}{ Otros } \\
\hline Especialmente & especialmente & especialmente & \\
\hline En especial? & En especial & & \\
\hline $\begin{array}{l}\text { Sobre todo?+sn } \\
\text { sin pausas }\end{array}$ & sobre todo & & adv. Enunciac \\
\hline & Principalmente & & \\
\hline Fundamentalmente & fundamentalmente & & advmodal-enunc. \\
\hline Particularmente & particularmente & particularmente & \\
\hline & Más que nada & & concreción \\
\hline En particular & & ordenador disc \\
\hline Antes que nada & $\begin{array}{l}\text { antes que nada, ante } \\
\text { todo }\end{array}$ & & limitativo \\
\hline Básicamente & básicamente & & \\
\hline
\end{tabular}


El operador de preferencia aparece entre pausas, aislado cuando va pospuesto. Antepuesto puede ir con o sin pausas. Incide sobre un sintagma, incluso precedido de preposición. Si es un adjetivo, afecta a la función que desempeña el adjetivo en la predicación. Frente a esto, el intensificador se combina con un adjetivo y modifica su grado. Aparece integrado entonativamente, sin pausas. A la intensificación añade cierto contenido cualitativo.

Las diferencias entre ellos pueden deberse a sus bases léxicas originarias. Sobre todo: potencia el valor locativo Antes que nada, ante todo: el orden discursivo. Más que nada: parecido a sobre todo. Pero más elevado en la escala. Principalmente: la importancia. Relacionado con básicamente Fundamentalmente y básicamente: lo básico Especialmente- sobresale por lo positivo. Añade un contenido evaluativo a la preferencia. Particularmente y en particular: poco esperado.

Por parejas están más relacionados: principalmente- fundamentalmente (más cercanos a la base léxica) Sobre todo- más que nada (por su constitución) Especialmente-particularmente (admiten la negación en su valor intensificador: «no especialmente» (particularmente) + adjetivo y son intensificadores de adjetivos).

Estos adverbios pueden organizarse en dos grupos según su grado de gramaticalización:

a) Los adverbios de preferencia, menos gramaticalizados:

preferiblemente, preferentemente, primordialmente, básicamente, esencialmente, fundamentalmente?, predominantemente.

b) Los operadores de preferencia y sobrerrealización: sobre todo, máxime, más que nada, ante todo, antes que nada, especialmente, particularmente, principalmente, en particular.

¿Más conclusiones? Este estudio revela muchas cosas sobre el proceso de gramaticalización de un elemento hasta hacerse operador, la diferencia entre valor léxico y operación discursiva, el límite entre operaciones como la concreción, la enfatización y la sobrerrealización, y cómo la fuerza argumentativa muestra diversos medios de manifestación.

Concretamente, la estructura general... particular presenta dos interpretaciones: concreción, y restricción - sobrerrealización.

En la primera hay una intención enunciativa: ejemplificar, concretar. Como efecto se produce un cierto relieve informativo.

En la segunda tenemos un proceso más complejo: a una enunciación añadimos en un segundo momento una restricción. Es un caso de reinterpretación. Pero sobre esa restricción opera el elemento que resalta y carga de fuerza en un nivel muy alto esa circunstancia. El proceso de perder extensión se compensa con una mayor intensión, una mayor fuerza. Y como consecuencia, se introduce una sobrerrealización. No todos los operadores de preferencia introducen esta sobrerrealización. Lo hacen: sobre todo, máxime, más que nada, ante todo, antes que nada, especialmente, particularmente, principalmente.

Esta estructura es interesante por la posición de los miembros y puede llevarnos a conclusiones sobre el orden de los elementos del enunciado. La posición antepuesta de un segmento con pausa se liga al marco informativo o argumentativo: función circunstante, 
complemento temático, foco, etc., Mientras que la pospuesta es de restricción. Es la posición de los complementos, de las circunstancias. Si estas aparecen con una pausa, se ponen de relieve. Se enuncian dos informaciones: una completa, otra restringida, y ambas tienen validez.

La posición inicial de un complemento realiza una función de marco, inclusiva. Sea circunstante o tópico, todo queda dentro de sus márgenes, lo abarca.

La posición pospuesta es restrictiva. Y sobre todo realiza esta función de restricción o especificación. Es un proceso de lo general a lo particular, una concreción y una pérdida de extensión. Por ello, algunos marcadores de este grupo tienen también un empleo como operadores de concreción: particularmente, en particular.

Por último, hay que destacar que en estas unidades el elegir un segmento como el más relevante (preferencia) va unido a una enfatización informativa y, en ocasiones, a un proceso de potenciación de su fuerza argumentativa. Un proceso complejo para el que nuestra lengua ha creado estos operadores.

\section{Referencias bibliográficas:}

Anscombre, J.C. (2001): "Surtout et particulièrement: le traitement des particules pragmatiques dans le cadre de la théorie des stéréotypes", en H. Ferrer - S. Pons (eds): La pragmática de los conectores y las partículas modales, Univ. Valencia, págs. 1-22.

DRAE: Diccionario de la lengua española. Real Academia Española, Madrid, Espasa, $22^{\mathrm{a}}$ ed. Fuentes, C. (en prensa a): "Hacia una sintaxis del enunciado", LEA, en prensa.

Fuentes, C. (en prensa b): "Operadores de intensificación del adjetivo: cantidad y evaluación", enviado a RILCE.

Fuentes, C.-E. Alcaide (2002): Mecanismos lingüisticos de la persuasión. Madrid, Arco Libros. Gezundhadjt, H. (2000): Adverbes en -ment et opérations énonciatives. Bruselas, P. Lang. Konig, E. (1991): The meaning of focus particles. New York, Routledge, Chapman \& Hale. Nolke, H. (1983): Les adverbes paradigmatisants: fonction et analyse. Revue Romane, 23.

- (ed., 1988): Opérateurs syntaxiques et cohésion discursive. Nyt Nordisk.

- (2001): Le regard du locuteur II. Paris, Kimé, 2001. «Les adverbes paradigmatisants révisés: non sur tout mais surtout sur surtout», págs. 271-297.

Santos Río, L. (1994): Apuntes paralexicográficos. I. El diccionario como pretexto. Salamanca, Gráficas Varona.

- (2003): Diccionario de particulas. Salamanca, Luso Española de Ediciones. 